IBIMA Publishing

Journal of Internet Social Networking \& Virtual Communities

http://www.ibimapublishing.com/journals/JISNVC/jisnvc.html

Vol. 2015 (2015), Article ID 828614, 10 pages

DOI: $10.5171 / 2015.828614$

Research Article

\title{
The Process of Identity Building In Second Life
}

\author{
Amira Gmidene ${ }^{1}$ and Jamel-Eddine Gharbi ${ }^{2}$ \\ ${ }^{1}$ Institute of Higher Commercial Studies of Carthage,University of Carthage \\ ${ }^{2}$ Faculty of economics and management of Jandouba, University of Jandouba,
}

Correspondence should be addressed to: Amira Gmidene; gmideneamira@hotmail.com

Received date: 24 February 2015; Accepted date: 18 April 2015; Published date: 26 October 2015

Copyright (C) 2015. Amira Gmidene and Jamel-Eddine Gharbi . Distributed under Creative Commons CC-BY 4.0

\begin{abstract}
Second Life is a 3D virtual world that had considerable echo in the world particularly among large companies that consider it as a pioneer for marketing research. The enigma of resident identity in Second Life must be raised in order to propose a research framework that can offer some answers to questions about the relationship between real and virtual, or even between real identity and virtual identity.This study explores the identity construction in the persistent world Second Life. The results of this study tend to define the process of building a virtual identity in Second Life and the factors associated with it. This research is supported on a qualitative study of 40 interviews conducted in immersion in the virtual world Second Life.
\end{abstract}

Keywords: Second life, virtual identity, identity building.

\section{Introduction}

Nowadays, we are seeing the emergence of a new field of research which is virtual worlds. They are defined as persistent 3D environments in which the resident moves and communicates with others through an avatar which is its graphic representation in the virtual world.

Second Life (SL) is a 3D virtual world accessible to the global population online totally designed by residents and offering free access. Besides being a space game, it is a platform for virtual construction of an alternative and real life thanks to the transactions and exchanges that are really made. In SL, the resident controls an "avatar" which is its graphic representation in 3D. Each avatar has a name and a profile card that contains information about the resident. The appearance of the avatar can be changed at any time (age, sex, size, color) according to the preferences of the resident that may choose a representation as close as possible to itself or to create an entirely different personality.

Indeed, the avatars have the opportunity to pay with real money, the life of their dreams and realize their growth in order to achieve a certain level of personal

Cite this Article as: Amira Gmidene and Jamel-Eddine Gharbi (2015), “The Process of Identity Building In Second Life", Journal of Internet Social Networking \& Virtual Communities, Vol. 2015 (2015), Article ID 828614, DOI: 10.5171/2015.828614 
satisfaction and to be appreciated by others in their virtual communities. What characterizes this new life is the freedom and autonomy of participants in the construction of their identities and the choice of activities and partners. As part of that freedom, participants adopt different strategies. Indeed, some maintain the same identity as the real life; others make changes in their appearances. Conversely, some achieve a complete rupture with their real identity. Previous research provides clarification about the strategies of identity construction in Second Life. However, the processes underlying this construction and explanatory factors of these strategies are currently unknown. Several companies are presently active in Second Life and remains how these companies can add value to the resident process of identity reconstruction. Indeed, the adaptation of firms to each of these processes is currently unknown.

The purpose of this study is to understand how Second Life users build their virtual identities and specifically about the process phases of identity construction. After the presentation of our theoretical framework, centered on a review of literature on identity and identity construction, the methodology of qualitative research and its contents are presented in a second part. This article closes with the presentation and discussion of results, theoretical and managerial contributions, as well as their limits.

\section{Theoretical Framework}

The notion of identity is a very old concept. It has already been treated by the preSocratic philosophers, and more than twenty centuries later it still attracts the attention of researchers. Indeed, the self and identity were among the topics most studied and were treated in a variety of disciplines such as psychoanalysis, psychology, etc... Erikson considers that identity is a multi-referential and polyvalent concept, and it was the crystallizer and the founder of the identity notion. He asserts that "identity is the subjective and tonic feeling of a personal unit (sameness) and of a temporal continuity (continuity)." (Erikson, 1968).
Mead appears as the exact opposite of Erikson. He states that "the self is not a substance but it is a process, an immense process" and underlines that the self is a social structure arising from daily interactions. (Mead 1934). Self is viewed as a set or series of identities that can be invoked individually or simultaneously in situations, but once evoked; individuals' actions are directed at having others verify an identity or identities.

The sociologist E. Goffman (1973) also highlighted the importance of the process of interaction between the individual and his environment in the preservation of its own identity. According to him, the "self presentation" is expressed by our behavior, our clothing, our words, etc.., to give a certain self-image, which we expect to be confirmed by others. In fact, in social interactions, individuals show a symbolic armory that allows them to play roles acceptable to others. The individual has several identities which updates within the constraints of the situation and according to his desires and interests (Goffman, 1973). The purpose of these roles is to establish satisfactory exchanges in social life where each individual plays his partition. Thus, Goffman believes that the person is characterized as a social actor playing a role.

\section{Identity building}

The construction of the identity of the person can be seen as a process of selfreflection that grow through time and space and depends on the interrelationship of the components of social and personal identity. Authors have shown that people begin to forge their identities as soon as they are aware of their bodies and then develop it through interaction with others while going through moments of crisis and continuous renewal. Indeed, they quote three phases of identity construction which are:

\section{- Phase 1: Corporeal identity}

In this phase there is a very important element in the construction of identity which is the "specular image" (Schilder 
1968). The latter is developing especially at the stage of mirror that constitutes the essential moment of identity construction. Wallon has shown that "in the mirror is often, with some kind of fascination and pleasure, that the child contemplates his image, a symbolic matrix in which the "I" is precipitated in a primordial form, before being objective in the dialectic of identification with the other.". At this stage, the individual discovers his body and come to identify himself. (Wallon 1949)

Certainly the corporeal identity grows from identifications that the has person of himself, but it also depends on the look of others and essentially feelings of similarity and difference with others. So this identity grows and emerges only through interaction with others.

\section{- Phase2: Interaction with Others}

As soon as he begins to identify himself, each person will attempt to communicate his identity and to make connections with others.

Mead (1934) argues that the child constructs his "I" in a socialization process. He affirmed that the child is fully aware of the possible structure of his "self" and the huge weight of the environment on it. Indeed, the child chooses his roles from the "stock of Roles" proposed by his group, these roles must necessarily correspond to the expectations of the community to which he belongs.

Stryker (1957) asserts that the child identifies the roles that suit him through interaction with society. Indeed, he defines the role identities as a particular social object that represents a dimension of the self. As a social object, a role-identity must necessarily be shared, socially recognized, and defined by action. In this sense a roleidentity serves as a link between the individual self and society." It happens so to choose, from many, an identity that allows him to keep in touch with members of his group and which offers a high level of psychological comfort.

\section{- Phase3: identity crises}

Erikson (1972) affirmed that the process of identity building sustain many unavoidable moments of crisis. He defined identity crisis as "the failure in the achievement of ego identity during adolescence"

Kaufman (2004) assumes that this phase is characterized by a social detachment. The individual tries to reject the imposed social frameworks to fit into a world that he chooses and in which he constructs his identity through multiple roles that he plays in society and the possible "selves" that he implements. "The possible selves represent the idea that the person is what he could become, what he would become, what he has afraid to become. They represent a kind of selection of virtual identities concretely feasible in a given situation. ".

The construction of identity is then a process that undergoes continuous changes and ruptures throughout the lives of persons.

\section{Identity Building in virtual spaces}

Since the appearance of cyberspace, and virtual spaces, the identity on internet becomes a topic of interest to many researchers. Indeed, in 1995, the American sociologist Sherry Turkle, published her book "Life on the screen: identity in the age of Internet" in which she addresses this concept in an academic way. She asserts that "Today, life ahead the screen dramatizes and concretizes a series of cultural trends that encourage us to think of identity in terms of multiplicity and flexibility." She has also studied the relationship established by the player with the game (machine) to implement strategies to win and to beyond his real self by forming a second self allowing him to reach his objectives in the game. She considered that computer users are borne away by the experiences that lead them to reject the notion of a "unitary self." (Turkle 1995)

Online, the player franchises certain borders and maintains a variety of roles 
and identity positions generally close of his "ideal self". He lives multiple experiences that arouse in him two types of feelings: a sense of relief or an unpleasant feeling of fragmentation.

In contrast to his real social environment, the virtual environment of the Internet user allows him to express an unlimited number of new "self" without any risk to be limited, discouraged or censored. In general, the "self" played on the Internet are socially and physically untenable in the real world. These virtual "selves" permit to the person to achieve desires and impulses unrealizable in real world. (Turkle 1995)

3D spaces (e.g., Second Life), came to offer to the user new possibilities for identity construction. In these areas the person is represented via an avatar that presents an interface between real and virtual. Indeed, "Through their character, players evolve in the game universe [...]. They are also connected with other players through the virtual identity of the avatar. They communicate by writing in the game through a chat system, similar to instant messaging, by which they express themselves mainly as a character and not as a player." (Grellier D. 2008)

Parmentier and Rolland, 2009 identified four postures in the relationship between the user and his avatar in Second Life (duplication, improvement, transformation and metamorphosis) in which residents have a relationship to the virtual world oriented to consumption or to creation and relation to oneself turned towards identity reinforcement or identity aperture.

\section{Methodology}

In order to properly conduct this study, we opted for an exploratory qualitative approach based on Grounded Theory due to the attention accorded to persistent worlds, which are nowadays a new field of research online, and the lack of information available concerning how the individual develops its identity between real world and virtual world. Grounded Theory meets a requirement of this research.
Many data sources can be used in the Grounded Theory such as: secondary data, life stories, interviews, observation, introspection and memos (Glaser 1967). In this research, we used three data sources: participant observation, life histories and semi-structured interviews. By respecting the criteria of theoretical sampling proposed by the GT, we developed a study with a sample of forty residents (40) between 18 and 40 year old from different nationalities and having a seniority of one (1) month to 5 years and belonging to different sites (different locations).

We used three levels of coding proposed by the Grounded Theory namely: open coding, axial coding and selective coding (Strauss and Corbin, 1998). Cope with the amount of data to process and which resulted from the open coding (more than two hundred pages of transcript), we used the software of qualitative data analyses Atlas.ti. The coding operation has enabled us to retain four main categories namely, the motivations of residents, practices, management of appearance and the behavior.

\section{Findings and Discussion}

\section{The process of identity building in Second Life}

The analysis of life stories and discourses of residents who relate to their lives in SL shows that life in SL begins when the resident decides to download the software of the game; it is at this time that appears the motivations of the resident in order to achieve his required goals. To clear the process of identity construction, we only use the words proposed by our respondents. To our knowledge, no previous research has addressed the underlying process for the construction of a virtual identity.

The testimonies stated that the second step of this path of life consists in the construction of a virtual identity which is to the creation of an avatar. This practice is central in virtual worlds because it allows access to the world and ensures the continuity and development of the 
resident. According to the residents, the choice of avatar is the starting time of the experiment, "the creation of the avatar is a moment of takeoff, this is where the adventure begins, it is the instant 0." (I.J). Indeed, the selection and creation of the avatar is an important moment in the virtual life of the resident. The avatar is a virtual projection of the individual and an interface between real and virtual. It can be characterized by many aesthetic and behavioral criteria.
Residents told us that they all passed through two essential phases in SL: Newbie phase and the phase of the personalized or experimented avatar. They described the activities they do during the two phases and the improvements they have made to their avatars. From their answers we tried to schematize the path of life of residents in SL (Fig. 1) to then conclude phases of identity construction process.

\begin{tabular}{|c|c|c|c|c|}
\hline T (-1) & T 0 & T 1 & T 2 & T3 \\
\hline \multirow[t]{6}{*}{$\begin{array}{c}\text { loading of } \\
\text { the } \\
\text { Software of } \\
\text { Second Life }\end{array}$} & \multirow{5}{*}{$\begin{array}{c}\text { Create an } \\
\text { account and } \\
\text { choose an } \\
\text { avatar, time of } \\
\text { arrival at the } \\
\text { island of Gaia }\end{array}$} & First meeting & $\begin{array}{c}\text { Dancing, } \\
\text { camping to save } \\
\text { money. }\end{array}$ & $\begin{array}{l}\text { Purchase or } \\
\text { lease of land }\end{array}$ \\
\hline & & $\begin{array}{c}\text { - Learning } \\
\text { standards and } \\
\text { key }\end{array}$ & Work & Building a family \\
\hline & & $\begin{array}{l}\text { - Discovery of } \\
\text { places. }\end{array}$ & $\begin{array}{l}\text { Opening a } \\
\text { premium } \\
\text { account }\end{array}$ & $\begin{array}{c}\text { Differentiation } \\
\text { between friends } \\
\text { and } \\
\text { acquaintances }\end{array}$ \\
\hline & & $\begin{array}{c}\text {-First trial of } \\
\text { personalization } \\
\text { of the Avatar }\end{array}$ & $\begin{array}{l}\text {-Learning of the } \\
\text { techniques of } \\
\text { construction }\end{array}$ & $\begin{array}{c}\text {-Provide helps to } \\
\text { newcomers }\end{array}$ \\
\hline & & (freebies) & \multicolumn{2}{|c|}{$\begin{array}{l}\text { Continuous personalization of the } \\
\text { avatar by purchasing clothing }\end{array}$} \\
\hline & \multicolumn{2}{|c|}{ Newbie Avatar } & \multicolumn{2}{|c|}{ Experienced Avatar } \\
\hline
\end{tabular}

Figure 1: path of life of residents in Second Life

\section{Standardization phase: the Newbie avatar}

Registration in Second Life involves the creation of a virtual identity to which must be accorded a name, a first name and a physical aspect selected from a list of twelve appearances suggested by the software. This starting phase is characterized by a similar appearance for all the beginners. This appearance is basic, standard and without any developed aesthetic characteristics. The beginning of the experience in SL, for our respondents, is a moment of strange emotions, exploration, disorientation, groping and hesitation. The initial goal for each resident is to decode the rules and become familiar with this huge space. This start-up period is very difficult to manage, in fact, residents 
have a gap between their real environment and this environment that they are just beginning to discover, a gap between what they want to do and what they can do.

The role of others in the initial phase seems essential to ensure the permanence and continuity in Second Life. From the beginning resident feels the importance of others and realizes the benefits of interaction. Our respondents state that they have established real amity with other avatars and they affirm that others residents are a source of support, especially at the beginning, which motivate them to be active and to evolve in the game. Sight of the similarity in appearance between him and the other, the resident will attempt to behave in a way that will make it distinct. Indeed, the resident can to choose to be single or to be integrated into groups and to make friendship relations with others.

This phase of standardization is very annoying for residents; the desire to be different and to stand out from others is the only concern of residents wanting to win the game and to ensure control of the space and maturity in this universe.

\section{Personalization phase: the evolution from a Newbie to an experienced user}

After some time spent in SL, the personalization of the avatar becomes a fundamental practice to ensure continuity in the game. To feel the change, the resident usually starts by changing his appearance to switch from a Newbie to a more prestigious avatar that represents him. The first attempts at customizing necessarily involve the acquisition of the freebies to prove mastery of the tools of game.

In this phase the presence of others has a great influence on the choice of the resident. Indeed, others help to change his appearance by giving gifts and offering "looks" or clothing styles that can help him to evolve gradually. The instructions of other residents also play a very important role, the desire to comply with group leads resident to shape his avatar according to the expectations of others. After a good immersive experience being autonomous and independent becomes undeniable for the resident. The interaction with other avatars (residents) allows residents to see that freebies do not provide him the desired change as they have undeveloped aesthetics characteristics.

It is from this time that the resident feels the need to think about the money and will pay money to change and develop its appearance. Practices will all be focused on saving money. Indeed, the respondents say that money is the unique way to guarantee differentiation and categorization in SL. The money allows residents to access to a multitude of choices and to a wide range of appearances and clothing styles. Personalization also affects behavior; the absence of the physical body will lead the resident to surpass the phase of disorientation and hesitation by customizing his behaviors that will become more and more safer in order to achieve the desired goals. In this phase the activities mutate, the resident will focus his activities on the virtual careers that play a very important role in the development of his virtual identity.

\section{Factors related to the construction of identity in Second Life}

At this stage, we should highlight the variables involved in the construction of identity. Indeed, after the analysis of different identity process we found that the construction of identity depends on several factors that have emerged fundamentally from practices, motivations and behaviors of residents. Among emerging concepts we have mention those that were most mentioned by residents and that we identified as determinant in the process of identity construction.

\section{The Culture}

The analysis of different practices of residents allowed us to see the importance of cultural activities in the evolution of SL. We have noted the existence of several communities of artists and a variety of places and cultural spaces. We also noticed 
the appearance of the term culture in several testimonies. According to respondent this term refers to the field of art and practices related to cultural and artistic production. Our respondents said that their cultural preferences intervene much when they create an avatar and the choice of the latter depends on their cultural status in real life or those which they hope to project in SL. "I am a painter, I tried to choose a crazy avatar like me! and that reflects what I am, full of color and full of life, an artistic avatar :)!! "

Generally artists in SL, keep their real identities, they adopt the same real artistic style but try to develop it using the functionality provided by the platform. They belong to groups of artists who know each other in real life and even communicate outside of SL.

They often choose avatars that reflect their artistic preferences and consider it a simple way to communicate with other artists. For them SL is a platform that facilitates artistic creation and help them to develop their skills freely and with minimal costs. Culture also allows residents to develop their environment and be very creative and open. Indeed SL becomes for them an artistic and cultural space that allows them to support their real cultural identities and enrich them through the multitude of cultures that exist in SL.

These communities of artists who grow day after day can be a particularly important target for enterprises wishing to set up in Second Life. Artists in Second Life are living from profits of their works; used to demonstrate their creative skills and abilities of familiarity with the tools they are provided. Companies can benefit from this creativity to create new products distributed in the real world and the virtual world. These companies can opt for cocreation, which consists in developing products or services in active collaboration with its customers, which generates lower risks and costs for the company. Marketing costs are reduced because the clients themselves convey a positive image of the company by word of mouth. The company also reduced the risk of being out of sync with the market because the products or services it launches on the market are much more suitable and attractive to customers that they have been co-created with them. The risk of not satisfying the customers is reduced significantly because they contributed to the construction of their satisfaction.

\section{The Commitment}

When analyzing data, especially data that relate to the management of the avatar, we found that residents who connect for the first time in SL, commit to choose an avatar that some projects or all of their true identities. They commit, in fact, to continue or not using their real identities. The term commitment appeared several times in the speech of residents when we ask them to describe their relationships with their avatars. "I feel committed to my identity, I want to convey it as it is I am proud to be like that!! ".

We could then distinguish two types of residents based on their level of commitment to their real identities:

- Those who are positively engaged to their real identities.

- Those who are negatively engaged to their real identities.

\section{Positive engagement}

Those who prove a positive commitment to their real identities greatly appreciate their identities and are not looking to try new. Second Life for them is a continuation of their real lives and believes that the avatar should project their identity as it is. In fact, they choose very close to their actual avatars physical appearances and plan all of their personalities. This joined the works of Parmentier and Rolland (2009) in fact we found that residents who engage positively to their identities generally adopt identity strategies of duplication or improvement. These two strategies assume that the resident has an avatar that is physically close to its appearance in the physical world and that reflects according to him the entire of his personality. These 
residents are wary of the virtual world and see it as an extension of the physical world that will allow obtaining new social relations, new skills, new ideas and new revenues (Parmentier and Rolland 2009).

For these residents, companies seeking to settle in Second Life must necessarily introduce the products of the real world and try to make connections between the two worlds as these residents are comforting in seeing real brands in the virtual world.

\section{Negative engagement}

These residents are weakly committed to their real identities. They say that there's nothing that holding them back to reality and seek to build an "ideal self" in an ideal world. These residents do not appreciate their real identities and do not wish to transfer them to the virtual world. They make a complete break between real and virtual, and consider Second Life as a way of reconstruction and self-invention. They create avatars that do not resemble to them and try to make changes in their appearances and personalities. We then noticed that these residents adopt strategies of metamorphosis and transformation proposed by Parmentier and Rolland (2009) who assume that these residents consider the virtual world as a platform to live another life and escape the physical world. The resident benefits of the virtual world to be physically which he cannot be in the physical world and to expose the best of himself.

For these residents, companies wanting to integrate this virtual platform must disconnect with reality. Products or services must be purely virtual and does not exist in the physical world. These companies can interact with these residents and invite them to participate in the creation of new products that meet their requirements.

\section{The Interaction}

During the various phases of the study (data collection and analysis) we noticed that the presence of the other is fundamental to the experience of living in SL and in the formation of the virtual identity of the resident. Indeed, residents benefit from interaction with others to develop their experience in Second Life and consider the opinion of the group is very important when customizing the avatar.

The role of others in the initial practice appears crucial to the success and the durability in Second Life: "It is very early that the sociability of the place shows us all his benefits."

Differently from role play, Second Life immediately puts out the "social factor" that characterizes it. Our respondents reported that they have established real relations of friendship with other avatars, and especially at the beginning, "others" are a source of support without which we would hardly want to stay in. "On the island of Gaia,[...] where I met people who gave me tips and explain how works the game".

Through interaction with others, the individual will be able to achieve a certain level of knowledge about him and to shape his self to ensure continuity in the group. Indeed, the physical closeness, the social context of the meeting proposed by SL and visibility of the appearance of the other, are often seen as basic factors for the preservation of social relationships and thus for the evolution of resident in the game. The "others" guide or help resident to make improvements, deletions or additions at his avatar. The resident negotiates his appearance and his identity with others who are in contact with theme. Others may also act indirectly. Indeed the pressure and influence of the virtual society create stereotypes to which the individual tries to conform and adapt.

The presentation of self in SL depends heavily on collaboration, sharing, contact with other avatars. Second Life can thus be likened to a theater stage where users can play several roles and change costumes to each role. The interaction between residents in Second Life therefore emerge rites, norms and social behaviors to follow, that contribute to the emergence of a social 
structure where residents seek to keep order.

\section{Conclusions}

Our research comes to enrich the previous research on virtual worlds, which are content to propose a classification of identity strategies in Second Life. Indeed, in this investigation we came to develop the underlying process of identity construction in Second Life. It helps to better understand how individuals appropriated virtual environments as tools for identity construction and offers an exploratory contribution to understand the type of action to take depending on the identity positioning of the resident. It shows that virtual worlds are spaces of simulation in which the individual tests their identity and are living multiple experiences.

At the managerial level, this research will enable managers to have an answer on the process of construction of virtual identities in Second Life to manage the various existing digital identities and thus their succeed operations targeting and positioning. In Second Life, the basis of operational marketing is fully challenged. It will be dangerous to offer products and services standard for the two worlds. The company wanting to establish themselves in SL must provide suitable offers and often co-constructed with the residents.

Despite its theoretical and managerial contributions, this research has some limitations. The first limitation is related to the subjectivity of qualitative research regarding the collection and analysis of data. Indeed, the method of interviews and life stories by Instant Messenger pose a problem of internal validity, in the sense that we are not sure of the credibility of respondents behind the screen. In addition, the choice of a convenience sample may reduce the external validity but increases internal validity. In addition, we have not developed rigorously factors related to the construction of identity. Therefore a quantitative study is needed to measure the effect of each one. So we only treated the interaction in one direction that relates to other effects exerted on the identity of the resident without considering the influence of the latter on the other. As our study focuses on a particular virtual world, thus, limiting the generalization of our findings.

Any time, we believe that our research can provide a starting point for further research to refine and improve the theoretical and empirical Approaches Linked to the virtual identity and marketing avatar. It will also be wise to complete this study by research for understanding the impact of virtual worlds on our reality and provide a comprehensive framework of action and possible offers in the universe.

\section{References}

1. Belk, R. (2006), Handbook of Qualitative Research Methods in Marketing, Edward Elgar, Toronto, Canada.

2. Bessière, K., SEAY, F. and Kiesler, S. (2007), "The ideal elf: identity exploration in world of warcraft", Cyber psychology and behavior, 10 (4).

3. Boellstorff, T. (2008), Coming of Age in Second Life: An Anthropologist explores the Virtually Human, Princeton University Press, Princeton.

4. Cogerino, A. (2009), " La construction de l'avatar sur second life: Un jeu de contraintes envers la réalité et la société virtuelle ", L'esprit du temps, 3 (69), 621629.

5. Erikson, E. (1972), Adolescence et crise, la quête de l'identité, Champs Flammarion Sciences.

6. Fuxa M. (2006), "Second Life, l'avènement d'un monde parallèle ", $E$ commerce $\mathrm{N}^{\circ} 5$ [Online], [Retrieved Janvier 25 , 2011], http://www.ecommercemag.fr/Ecommerce/Article/Second-Life-lavenement-d-un-monde-parallele-227261.htm.

7. Glaser, B. and Strauss, A. (1967), The Discovery of Grounded Theory: Strategies 
for Qualitative Research, Aldine De Gruyter, New York.

8. Goffman, E. (1973), La mise en scène de la vie quotidienne, Tome 1 et 2, Editions de Minuit, Paris.

9. Grellier, D. (2008), "Du joueur au personnage, sexuation des rôles dans les jeux de rôle en ligne massivement multijoueurs", Actes du colloque «Genre et transgression. Par-delà les injonctions... un défi ? ", Mission Egalité des Chances, Université Paul-Valéry, Montpellier III.

10. Iteanu, 0. (2008), Identité numérique en question, Éditions Eyrolles, Paris.

11. Jones, D.E. (2008), " I Avatar: Constructions of Self and Place in Second Life and the Technological Imagination ", The peer-reviewed journal of Communication, Culture and Technology, 2 (2), 33-66

12. Joule, R. and Beauvois, J. (1989), "Une théorie psychosociale: la théorie de l'engagement", Recherche et Applications en Marketing, 4(1), 79-90.

13. Kaufmann, J.C. (2004), L'invention de soi, une théorie de l'identité, Hachette Littératures, Calman-Lévy, Paris.

14. Marc, E. (2005), Psychologie de l'identité : Soi et le groupe, Dunod, Paris.
15. Mead, G.H. (1963), L'esprit, le soi et la société, PUF, Paris.

16. Parmentier, G. and Rolland, S. (2009), "Les nouveaux consommateurs des mondes virtuels: construction identitaire et expérience de consommation dans Second Life", Recherche et Applications en Marketing, 24(3), 43-56.

17. Rosedale, P. (2007), Second life: the official guide, Wiley publishing Inc ; Indianapolis, Indiana.

18. Straus, A. and Corbin, J. (1998), Basics of Qualitative Research: Techniques and Procedures for Developing Grounded Theory, 2nd Edition, Sage Publications, London.

19. Stryker, S. (1957), "Role-Taking Accuracy and Adjustment ", American Sociological Association, 20(4) , 286-296.

20. Tisseron, S. (2008), "Internet est un immense bal masqué", Le Figaro Madame[Online], [Retrieved Février 15,2010],

http://madame.lefigaro.fr/societe/internet -immense-bal-masque-060208-10840.

21. Turkle, S. (1995), Life on the Screen Identity in the Age of the Internet, Simon and Schuster, New York.

22. Wagner, J.A. (2008), The Making of Second Life, Harper Collins, New York 